\title{
POR UMA HISTORIOGRAFIA DA FORMAÇÃO DE PROFESSORES DE PORTUGUÊS COMO LÍNGUA ESTRANGEIRA ${ }^{1}$
}

\section{Towards a historiography of Portuguese as a foreign language teacher training}

\author{
José Marcelo Freitas de Luna*
}

\begin{abstract}
RESUMO
O presente artigo deriva de uma pesquisa historiográfica sobre o ensino de português como língua estrangeira nos Estados Unidos durante as décadas de 40, 50 e 60 do século XX. Guiando-nos por Koerner (1995), em sua referência particular ao princípio de contextualização, e tendo como fontes primárias os livros, periódicos e jornais da época encontrados nas bibliotecas de algumas universidades americanas, descrevemos, pontualmente, o clima de opinião da determinante da formação de professores de línguas estrangeiras. Essa descrição permite-nos interpretar o clima de opinião do período como favorável ao Brasil, fato que implicará a escolha e a promoção de uma variante chamada brasileira para o ensino de português nos Estados Unidos.

Palavras-chave: Português como língua estrangeira; historiografia; formação de professores.
\end{abstract}

\begin{abstract}
The present article derives from a historiographical research on the teaching of Portuguese as a foreign language in the United States during the period of 1940 through 1960. Following Koerner (1995), in particular his reference to the principle of contextualization, and having as primary sources the books, periodicals and newspapers of the time found in the libraries of some American universities, we objectively describe the climate of opinion which determined the foreign language

* UNIVALI.

${ }^{1}$ Trabalho derivado de pesquisa de pós-doutorado, com apoio da Capes, processo $\mathrm{n}^{\circ} \mathrm{BEX}$ 0384/10-0, durante o período de 2010/2011 na Universidade do Texas, em Austin.
\end{abstract}


teacher training. This description allows us to interpret the climate of opinion of the decade as favorable to Brazil and to the selection and promotion of the so called Brazilian variant for the teaching of Portuguese in the United States.

Keywords: Portuguese as a foreign language; historiography; teacher training.

\section{ConsideraçõES InICIAIS}

O ensino de Português como Língua Estrangeira (doravante PLE) nos Estados Unidos destaca-se como nosso interesse particular por razões que, a partir de uma perspectiva historiográfica, podem estar inter-relacionadas. Referimo-nos ao movimento, quase desconhecido no Brasil, de mais de três séculos de implantação do PLE naquele país, marcados, nos termos de alguns pesquisadores, "por altos e baixos". Referimo-nos, paralelamente, à tradição americana na área de Linguística Aplicada ao ensino de línguas, e à formação e ao desenvolvimento de grupos e associações de professores de PLE em algumas universidades dos Estados Unidos.

Para dar conta da reconstrução das práticas linguísticas passadas, a Historiografia da Linguística (doravante HL) assume explorar a dimensão pessoal, que se relaciona com o papel dos agentes no processo de desenvolvimento do conhecimento, bem como a dimensão social, a qual identifica o contexto e as suas influências sobre o conhecimento linguístico.

É por ter esse objetivo que a importância do estudo historiográfico se evidencia para os profissionais da linguagem e para a própria Linguística. Segundo Koerner (1989), o conhecimento histórico acerca de sua disciplina é o que caracteriza um "verdadeiro cientista". Ao conhecer a origem e as limitações dos pressupostos teóricos e dos métodos, o pesquisador habilita-se a lidar com problemas imprevistos e com mudanças de interpretações, e a reconhecer os avanços reais, no seu campo, de variações deste mesmo campo ao longo do tempo.

Apesar de representar um relevante objeto de pesquisa para a Linguística, além de uma fonte valiosa de conhecimento sobre a natureza e o status da língua portuguesa e da identidade e cultura brasileiras no mundo, a historiografia do ensino do português no exterior ainda se encontra em estágio de produção incipiente.

No presente artigo, apresentamos os resultados de uma pesquisa sobre o PLE nos Estados Unidos durante as décadas de 40 a 60, tendo como foco a influência do clima de opinião na formação de professores do chamado português do Brasil. Trata-se de um levantamento, a partir de 
fontes primárias como livros, artigos de periódicos e de jornais da época, do contexto sócioeconômico e político-estratégico, bem como das concepções linguísticas que caracterizam a época.

\section{Registros do Ensino do Português do Brasil nos Estados Unidos}

No artigo "The Place of Portuguese in American Education", publicado no periódico Education, em fevereiro de 1942, Charles R. D. Miller se reporta ao trabalho, considerado por ele pioneiro, de Pietro Bachi. Registros dão conta de que, em 1831, este professor de nacionalidade italiana esteve ligado ao departamento de línguas modernas da Universidade de Harvard, publicando um livro intitulado Comparative view of the Spanish and Portuguese Languages and an easy method of learning the Portuguese tongue for those who are already acquainted with Spanish.

O uso desse livro, ou pelo menos a prática que teria dado a motivação e a experiência para tal, viria de aulas de português na Universidade de Harvard. A dedicatória que o autor faz aos seus alunos é comprovação disso:

Aos estudantes da Universidade de Harvard, para cujo uso e a pedido de quem este livro foi compilado [...] como um tributo por sua dedicação às belas-letras. (citado em MILLER, 1948, p. 351, tradução nossa). ${ }^{2}$

Relatórios de diversas instituições e artigos sobre o ensino de línguas, desenvolvidos ao longo do final do século XIX e primeiras quatro décadas do século XX, dão conta de que o português foi ensinado nos Estados Unidos, esporádica e ocasionalmente. No entanto, todas as fontes consultadas servem de base para a afirmação de que é com o advento da Segunda Guerra que o quadro de irregularidade de oferta de cursos de línguas estrangeiras em geral e do português em particular começa a mudar.

A sociedade e as instituições americanas, que tinham, durante a Primeira Guerra, desmerecido a língua e a cultura do inimigo e repudiado qualquer coisa que pertencesse a ele, passam, na Segunda Guerra, a querer aprender a língua dos povos com países com os quais os Estados Unidos estavam envolvidos, fosse como inimigo ou como aliado. Objetivamente,

${ }^{2}$ To the students of Harvard University, for whose use and at whose request it was compiled [...] as a tribute to their zeal for polite learning. (cit. em MILLER, p. 351). 
a motivação era militar e estratégica, mas também política e econômica; visava ao período da guerra em si, mas também ao que viria depois como, por exemplo, as oportunidades de negócios.

É assim que o Brasil começa a ser visto e referido nas mais diversas publicações do período, não só aquelas especializadas em ensino de línguas e educação, como também em negócios e política externa. No mesmo artigo citado acima, percebe-se o papel visto para o Brasil e aquele de Portugal, ambos usados como argumentos para o interesse e a prática do ensino de português nos Estados Unidos:

Desde o começo da Guerra em 1939 a situação mudou radicalmente. Sendo Lisboa o único importante porto em território neutro no Atlântico Europeu, Portugal começou a pairar nos noticiários todos os dias. Mais importante tem sido o interesse crescente, causado pela guerra, em todos os países da América Latina e a consequente constatação da importância do Brasil. (MILLER, 1942, p. 351, tradução nossa). ${ }^{3}$

Algumas escolas, nesse período, fizeram consultas abertas aos seus alunos a respeito da língua estrangeira que gostariam de aprender, numa tentativa expressa de planejar a oferta da disciplina com base nas necessidades dos alunos. No artigo "Why I Chose to Study a Foreign Language", publicado, em 1941, no The Modern Language Journal, a autora se reporta à pesquisa feita com os alunos de uma escola de Chicago, apresentando o questionário usado para tal. Nele, podem-se encontrar basicamente questões relacionadas à motivação instrumental, como preparação para uma profissão ou negócios nos Estados Unidos ou em um país estrangeiro.

Hutton (1945), na mesma linha, chega a listar algumas oportunidades de emprego para profissionais com conhecimento de línguas, em particular de espanhol e de português. Ela diz:

Nossos recentes programas internacionais na área de agricultura, engenharia, e química, por exemplo, requerem o emprego de homens e mulheres que tenham a habilidade para falar o espanhol e o português. Há necessidade de tradutores no campo do direito, do

\footnotetext{
${ }^{3}$ Since the outbreak of the present war in 1939 the situation has changed radically. With Lisbon the only important European Atlantic seaport in neutral territory, Portugal began to loom large in the daily news. More important has been the growing interest, caused by the war, in all the LatinAmerican countries and the consequent realization of the importance of Brazil. (MILLER, 1942, p. 351).
} 
comércio, da indústria editorial, do turismo e do rádio. (HUTTON, 1945, p. 24-25, tradução nossa). ${ }^{4}$

Berrien (1945), por sua vez, se refere explicitamente a usos da língua por parte de pessoal mais graduado, como uma profissão definida e com objetivos acadêmicos ligados à pesquisa de temas e objetos do Brasil:

[...] para dar ao antropólogo ou ao sociólogo um interesse em adquirir o português para estudar os abundantes materiais brasileiros que lidam com problemas de relações sociais, aculturação, e ajustamento social. (BERRIEN, 1945, p. 47). ${ }^{5}$

Referências à importância do chamado português do Brasil para áreas de atuação além daquelas das forças armadas podem ser tomadas como características de um clima de opinião favorável à profissionalização da carreira docente do PLE nos Estados Unidos. É exatamente em torno desse objeto em particular que a seção abaixo se justifica e se organiza.

\section{Fatos determinantes da formação de professores de Português nos Estados Unidos}

Como apontado acima, uma referência comum a quase todos os textos nessa linha, digamos, motivacional para o aprendizado do português é à oportunidade da carreira como professor dessa língua nos Estados Unidos. Durante um período em que se estimulava o ensino, não podia deixar de haver a preocupação com o fomento à vocação docente para a disciplina e para a preparação de professores.

Esse aspecto só é bem considerado na década de 60, com o National Defense Education Act (NDEA) ${ }^{6}$ e seus investimentos pontuais na formação

${ }^{4}$ Our recent international programs in the field of agriculture, engineering, and chemistry, for example, require the employment of men and women who have the ability to speak Spanish and Portuguese. There is a need for translators in the fields of law, commerce, the publishing industry, guide service, and radio. (p. 24-25).

${ }^{5}[\ldots]$ to give the anthropologist or sociologist an interest in acquiring Portuguese in order to study abundant Brazilian materials dealing with problems of race relations, acculturation, and social adjustment. (p. 47).

${ }^{6}$ Assinada em 2 de setembro de 1958, esta lei federal foi instituída para fomentar o desenvolvimento da educação nos Estados Unidos, com provisões específicas para o ensino de línguas estrangeiras nas escolas e universidades americanas. 
docente. Sobre a década de 40, contudo, quem se manifesta ilustrativamente sobre esse assunto, destacando, a propósito, o português do Brasil, é Roby (1945):

Há no momento uma carência de professores de português. Nós precisamos especialmente de professores da língua como falada no Brasil, uma vez que o uso maior que faremos da língua será para nos relacionarmos com o Brasil e não com Portugal e suas possessões. (ROBY, 1945, p. 53, tradução nossa). ${ }^{7}$

Se, por um lado, a profissão de professor de línguas estrangeiras era apontada como importante para o país nos anos 40, por outro, a preocupação com o seu crescimento no período pós-guerra marcaria intensamente o final da primeira metade dessa década.

De fato, a discussão acerca da real demanda por professores de línguas estrangeiras para as escolas e universidades americanas tomaria boa parte da agenda dos encontros da categoria. Isso porque a maioria dos profissionais formados e em formação se sentia insegura em relação à manutenção do Army Specialized Training Program (ASTP) e, consequentemente, à sua empregabilidade. Dito de outra forma, os professores de línguas estrangeiras, principalmente aqueles que não tinham sido incluídos no programa das forças armadas, se perguntariam a respeito do interesse dos americanos em geral de aprender o português, entre outras línguas, ao longo dos anos que se seguiriam.

A inquietação dos docentes fez gerar manifestações formais de profissionais e de associações de línguas estrangeiras dos Estados Unidos. Expressas em artigos de diversas revistas especializadas da época, essas manifestações seriam de encorajamento para os professores do país e de otimismo em relação ao seu mercado de trabalho futuro. A fala mais emblemática nesse sentido é de Mario A. Pei, durante o Encontro Anual da New England Modern Language Association (Associação de Língua Moderna da Nova Inglaterra):

Minha mensagem para os professores reunidos na assembléia foi de esperança e de oportunidade ilimitadas. As profecias otimistas que pronunciei não se basearam em desejos meramente; elas

${ }^{7}$ There is at present a shortage of teachers of Portuguese. We need especially teachers of the language as it is spoken in Brazil, since our chief use of the language will be in connection with Brazil rather than Portugal and its possessions. (p. 53). 
se basearam nas notícias que não param de chegar do front da guerra, [...]; dos fronts dos jornais e das revistas, [...]; e do front das livrarias, [...]. Há alguma razão para achar que a necessidade da língua será menor no período do pós-guerra, sendo os meios de comunicação o que são hoje, e os problemas de reconstrução o que serão? Se há alguma coisa, as indicações são de que mais e mais pessoas, treinadas em mais e mais línguas, vão ser mais e mais urgentemente demandadas. (PEI, 1944, p. 280 e 284, tradução nossa). ${ }^{8}$

Pela relação direta que guarda com a formação e atuação de professores de línguas estrangeiras, convém nos reportarmos à situação do material didático para o ensino de português na década de 40. Isso deverá servir como indicação de que a retórica de carência de um livro para a prática, que se fazia estimulada e crescente, já era usada pelos professores e pesquisadores, alguns dos quais autores de artigos sobre esse assunto. Um dos primeiros que se manifestaram é o próprio Miller, em fevereiro de 1942. Revisando os títulos então disponíveis, ele conclui:

Os professores de Português têm todos enfrentado o problema sério de encontrar textos adequados para leitura e material para exercícios em composições e conversação. (MILLER, 1942, p. 352, tradução nossa). ${ }^{9}$

A demanda por estudos e materiais didáticos aplicáveis à situação de ensino do português do Brasil na década de 40 apresenta-se bem claramente em um projeto que resultaria no livro, publicado em 1945, com o título Handbook on the Teaching of Spanish and Portuguese, editado por Henry Grattan Doyle, então editor de Hispania, com a colaboração de outros profissionais envolvidos com o ensino de línguas nos Estados Unidos. O objetivo expresso era responder a questões que estariam sendo feitas por professores dessas duas línguas, o espanhol e o português, em todo o país. As

\footnotetext{
${ }^{8}$ My message to the assembled teachers was one of boundless hope and boundless opportunity. The optimistic prophecies I uttered were not based on mere wishful thinking; they were based on the news that kept pouring in from the war-fronts, $[\ldots]$; from the newspaper and magazines fronts, $[\ldots]$; and from the bookshop front, [...]. Is there any reason to think that this language problem will become abated in the postwar period, with means of communication what they are today, and the problems of world reconstruction what they will be? If anything, the indications are that more and more people, trained in more and more languages, will be more and more urgently needed. (p. 280 e 284).

${ }^{9}$ Teachers of Portuguese have all been faced with the serious problem of finding adequate texts for reading and material for exercises in composition and conversation. (p. 352).
} 
respostas assim pretendidas encontram-se nos capítulos, que se podem dizer organizados como temas relacionados à motivação para ensinar e aprender as línguas, como fazê-lo metodologicamente e com que recursos contar.

Ainda sobre a década de 40 e a sua importância para o desenvolvimento da formação de professores para o ensino de português nas décadas que se seguiriam, faz-se necessário destacar a (re) organização de uma das mais importantes associações de professores dos Estados Unidos. Referimo-nos a The American Association of Teachers of Spanish (Associação Americana de Professores de Espanhol). Criada em 1917 a associação vinha desde praticamente essa data tratando dos assuntos e dos interesses relativos à língua portuguesa nos Estados Unidos. No entanto, é em 1944, no seu encontro anual, que a então ATS troca o seu nome para The American Association of Teachers of Spanish and Portuguese (ATSP - Associação Americana de Professores de Espanhol e de Português). Repercute, assim, o clima de opinião favorável ao português, particularmente ao português do Brasil.

Para bem caracterizarmos a década de 40 e, assim, podermos relacioná-la à formação docente é também digna de nota a realização, ao longo dos anos de 1944 e 1945, das Conferences on the Teaching of Spanish and Portuguese (Conferências sobre o Ensino de Espanhol e de Português). Promovidas pela Associação Nacional de Educação, com recursos do Escritório de Assuntos Interamericanos, essas conferências foram feitas em vários estados do país, tendo como objetivo a discussão de temas como:

O lugar das Línguas Hispânicas e das línguas em geral na formação do cidadão do mundo; os objetivos do ensino de línguas estrangeiras; a aplicação, na sala de aula em geral, da experiência do exército com o ensino de línguas estrangeiras; os novos materiais de ensino; o espanhol na escola elementar; e a preparação de professores de línguas estrangeiras. (NICHOLS, 1945, p. 130, tradução nossa) ${ }^{10}$

Para os professores de línguas estrangeiras, os anos 40 chegam ao seu final com renovada esperança de manutenção do crescimento de interesse e de matrículas nos cursos de línguas, ao longo dos anos que se seguiriam. No entanto, o que aconteceu imediatamente após a Segunda Guerra foi uma diminuição na demanda por línguas estrangeiras: "De 1947 até o outono de

\footnotetext{
${ }^{10}$ The place of the Hispanic Languages and languages in general in training for world citizenship; the objectives of their teaching; applications to civilian classes of the Army experience with language classes; new teaching materials; Spanish in the elementary school; and preparation of foreign language teachers. (NICHOLS, 1945, p. 130).
} 
1953, as matrículas em língua estrangeira nas faculdades caíram anualmente em percentagem" (PARKER, 1961, p. 92, tradução nossa). ${ }^{11}$ Isso se deu, de acordo com a análise de alguns autores de estudos dessa época, por razões que podemos caracterizar como inter-relacionadas.

Como vimos, a Segunda Guerra tinha feito gerar a preocupação com a falta de conhecimento de línguas estrangeiras dos militares americanos, fato que viria a determinar o desenvolvimento do chamado Army Method. A partir do que se pode chamar de uma verdadeira publicitação dos seus bons resultados na preparação de alunos para falar e compreender uma língua estrangeira em situações reais do dia a dia, podemos dizer, parafraseando Parker (1961), que os Estados Unidos descobriam o Army Method. Como consequência, a sociedade americana passava a desacreditar de vez na abordagem tradicional a que seus jovens vinham sendo expostos até então.

De fato, a adaptação do método a uma situação diferenciada daquela das forças armadas é objeto de uma série de artigos, publicados em diversas revistas especializadas em educação. Mesmo aqueles autores absolutamente simpáticos ao uso do método nas escolas em geral não desconsideraram as características originais do Army Method. Para produzir os resultados propagados (aqui não nos cabe avaliar a legitimidade desse fato em si), os requisitos tomados pelas escolas militares eram, segundo Parker (1961), os seguintes:

(1) Carga-horária ampla - os "9 meses" do exército eram equivalentes a 6 anos de estudo de língua da escola média; (2) turmas muito pequenas; (3) professores superlativamente treinados - frequentemente dois instrutores por sala, um sendo falante nativo; (4) equipamento moderno; (5) estudantes com alto QI e com uma motivação forte para estudar línguas; e, por fim, (6) concentração no estudo da língua em detrimento de todo o resto. (PARKER, 1961, p. 91 , tradução nossa). ${ }^{12}$

Se, por um lado, não havia dúvida acerca da importância e da necessidade de conhecimento de línguas estrangeiras por parte da sociedade americana, por outro, certo ceticismo com relação ao alcance dos resultados

\footnotetext{
11 "From 1947 until the fall of 1953, modern foreign language enrollments in the colleges dropped annually in percentage." (PARKER, 1961, p. 92).

${ }^{12}$ (1) Ample time - hour for hour the Army's "9 months" were equivalent to 6 years of high school language study; (2) very small classes; (3) superlatively trained teachers - frequently two instructors per class, one a native speaker; (4) up-to-date equipment; (5) students with a high IQ and with a strong motivation for language study; and, finally, (6) concentration on language study to the exclusion of everything else. (p. 91).
} 
das escolas militares em situação escolar comum tomou conta de professores e das famílias.

A carga-horária disponível para o ensino de línguas estrangeiras nas escolas não parecia compatível com o regime intensivo característico do Army Method; os professores, em geral, não se mostravam preparados o suficiente e tampouco eram avaliados como tal para o uso da abordagem audiolingual; quase a totalidade das escolas não dispunha de laboratórios de línguas, recurso apontado por muitos linguistas de então como indispensável ao desenvolvimento das aulas; os alunos não eram militares e não teriam a sua mesma motivação e dedicação para os estudos.

De fato, o currículo em geral das escolas dos Estados Unidos foi objeto de muita discussão nesse período. A pergunta que educadores e críticos especializados se faziam era basicamente sobre o que ensinar às crianças. A resposta significaria a revisão de teorias educacionais, particularmente daquela associada a John Dewey desde o início daquele século. É exatamente no começo dos anos 50 que os especialistas e críticos da educação progressiva e do "life adjustment" reclamam mudanças.

É nesse contexto que o conhecimento de línguas estrangeiras começa a ser abordado pela sociedade americana e, logo depois, pelo governo federal como "interesse nacional". Marcando decisivamente esse clima de opinião favorável a línguas estrangeiras em geral e ao português do Brasil, a Modern Language Association (Associação de Línguas Modernas) lança, com recursos da Fundação Rockfeller, o MLA Foreign Language Program (FLP - Programa de Língua Estrangeira). Expressamente, os objetivos deste Programa eram encorajar e melhorar o estudo de línguas estrangeiras em todo o sistema escolar dos Estados Unidos.

Para torná-los mais conhecidos dos professores de línguas do país, o Comitê Executivo do FLP realizou eventos próprios e participou de diversas conferências de associações regionais. Em todos os lugares, explicações a respeito da concepção de língua e da abordagem para o ensino seriam apresentadas e discutidas, chegando ao consenso e à consequente aprovação, em 1956, de um relatório do Comitê nos seguintes termos:

O estudo de uma língua estrangeira é tanto uma experiência progressiva quanto uma aquisição progressiva de uma habilidade.

1. Os contatos internacionais e as responsabilidades dos Estados Unidos tornam a possessão destas habilidades por mais e mais americanos como um problema de urgência nacional. Estas habilidades incluem:

a. A habilidade crescente para compreender uma língua estrangeira quando falada. 
b. A habilidade crescente para falar a língua estrangeira em comunicação direta.

c. A habilidade para ler a língua estrangeira.

2. Uma nova compreensão da língua, progressivamente revelando ao aluno a estrutura da língua.

3. Um conhecimento crescente e profundo de um país estrangeiro - a sua geografia, história, organização social, literatura e cultura. (citado em JOHNSTON, 1956, p. 72, tradução nossa). ${ }^{13}$

No fim de 1957, o debate educacional parecia convergir para a necessidade de ampliação do número de línguas estrangeiras oferecidas nas instituições escolares do país e da melhoria do seu ensino, particularmente através da ênfase na produção e compreensão orais associadas à abordagem audiolingual.

Esse clima favorável seria intensificado com um fato ainda não esquecido pelos americanos: o lançamento pela então União Soviética, em 4 de outubro de 1957, do Sputinik I. Esse fator extralinguístico se desdobraria em questionamentos dos mais diversos setores da sociedade sobre a competência dos cientistas e educadores de forma geral. Um exemplo típico do tom usado para isso pode também ser visto em revistas de circulação nacional naqueles dias, como este de autoria de Edward Teller e publicado na US News and World Report:

Nos anos que virão, os russos vão estar na nossa frente em ciência e no campo que a ciência gera, chamado de tecnologia. Se isso acontecer, eu acho que não haverá dúvida de quem vai determinar o futuro do mundo. Nós sofremos um golpe muito sério em um campo onde pelo menos alguns dos mais importantes compromissos estão sendo realizados: a sala de aula. (TELLER, 1957, p. 65, tradução nossa). ${ }^{14}$

of a skill.

${ }^{13}$ The study of a foreign language is both a progressive experience and a progressive acquisition

1. The international contacts and responsibilities of the United States make the possession of these skills by more and more Americans a matter of national urgency. These skills include:

a. The increasing ability to understand a foreign language when spoken.

b. The increasing ability to speak the foreign language in direct communication.

c. The ability to read the foreign language.

2. A new understanding of language, progressively revealing to the pupil the structure of language.

3. A gradually expanding and deepening knowledge of a foreign country - its geography, history, social organization, literature, and culture. (citado em Johnston, 1956, p. 72).

${ }^{14}$ In the coming years the Russians will forge ahead of us in science, and in the field that science generates, namely technology. If that should come to pass, I think there can be no doubt who will determine the future of the world. We have suffered a very serious defeat in a field where at least some of the most important engagements are being carried out: in the classroom. (p. 65). 
Essas cobranças chegariam imediata e diretamente ao governo federal, sendo reconhecidas por Washington como procedentes. O presidente Eisenhower, em uma série de discursos sobre o assunto, apoiar-se-ia em relatórios sobre a educação na União Soviética em comparação àquela dos Estados Unidos. No segundo "reassurance speech", feito no dia 13 de novembro em cadeia nacional da cidade de Oklahoma, ele se dirige aos professores das escolas americanas, enfatizando a educação como um aspecto de segurança nacional do país:

A União Soviética agora possui - considerando as categorias cientistas e engenheiros como uma só - um número maior do que a dos Estados Unidos. E eles estão formando profissionais para essas áreas de forma mais rápida. [...] Esta tendência é preocupante. De fato, e de acordo com meus conselheiros para a área da ciência, este problema é o maior de todos para o povo americano. Examinem os seus currículos escolares e os seus padrões. Depois decidam vocês mesmos se eles correspondem às demandas da era em que estamos ingressando. (PUBLIC PAPERS, 1957, p. 814-817, tradução nossa).$^{15}$

O satélite soviético serviria, assim, como um catalisador, ao trazer os debates sobre a educação do país, que já vinham ganhando e representando verdadeiras forças anos antes, para o plano das decisões e dos financiamentos governamentais. Em 2 de setembro de 1958, o Presidente Eisenhower assina o National Defense Education Act (Lei da Educação como Defesa Nacional), lei que se tornaria histórica para o ensino de línguas estrangeiras e para a formação de professores de português nos Estados Unidos.

O NDEA, assinado como lei em 2 de setembro, é um fato que merece destaque, em especial o seu Título VI: "Provê de várias formas assistência financeira para o ensino de línguas estrangeiras e a melhoria do ensino". Como concebido, foram estabelecidos quatro grandes programas: os Institutos para Professores de Línguas Estrangeiras Modernas das Escolas Elementares e Secundárias; Bolsas de Estudos para alunos avançados de línguas estrangeiras criticamente necessárias e de matérias a elas relacionadas; centros

${ }^{15}$ The Soviet Union now has - in the combined category of scientists and engineers - a greater number than the United States. And it is producing graduates in these fields at a much faster rate. [...] This trend is disturbing. Indeed, according to my science advisors, this is for the American people the most critical problem of all. [...] Scrutinize your school's curriculum and standards. As you do this, my friends, remember that when a Russian graduates from high-school, he has five years of physics, four years of chemistry, one year of astronomy, five years of biology, ten years of math through trigonometry, and five years of foreign language. (Public Papers, 1957, Washington, D.C., p. 817). 
de língua e de área de universidades; pesquisa e levantamentos relativos às línguas estrangeiras e ao seu ensino.

De acordo com Hamilton (1963), três anos depois da assinatura do NDEA, ou seja, em 1961, um staff especial foi acrescentado ao Language Development Branch (Setor de Desenvolvimento das Línguas) "como um reconhecimento da importância crítica da Aliança para o Progresso, para dar impulso aos estudos latino-americanos através desses quatro programas" (1963, p. 4; tradução nossa). ${ }^{16}$ Essa medida de 1961 é de fato uma resposta a muitas cobranças feitas pelos centros de estudos latino-americanos, que tinham se formado ou que desejavam ser ampliados, a partir do NDEA, nas universidades dos Estados Unidos.

Foi para bem caracterizar a situação dos estudos latino-americanos no país que se realizou, em novembro de 1958, um evento financiado pelo American Council of Learned Societies e pela Newberry Library. A retórica de reivindicação dos professores envolvidos com os estudos latino-americanos em geral e com os estudos de língua portuguesa e do Brasil em particular pode ser encontrada no Relatório "Latin American Studies in the United States", citado em Letgers (1965):

O encontro produziu concordância geral sobre áreas ou matérias que tinham sofrido negligência dentro dos estudos latino-americanos. Os participantes sentiram o estudo da língua do Brasil e de Portugal constituía um campo integralmente negligenciado e que para toda a área apenas antropologia, geografia, história colonial e literatura haviam recebido atenção razoavelmente adequada. (s/n; tradução nossa) ${ }^{17}$

Para a implementação das provisões do Título VI, seria necessária a identificação das línguas estrangeiras pouco estudadas e consideradas de interesse nacional no país. Seriam mapeadas, assim, as línguas críticas ou negligenciadas nos Estados Unidos, terminologia que significava o status de língua pouco estudada em que pesasse a sua importância para o país.

A avaliação da condição de oferta de cada língua estrangeira em escolas e universidades do país, com foco principal no número de matrículas,

\footnotetext{
16 "as recognition of the critical importance of the Alliance for Progress, to give impetus to Latin American studies through these four programs." (p. 4).

${ }^{17}$ The meeting produced overall agreement on particular fields or subjects that had suffered from neglect within Latin American studies. The participants felt that Brazil and Portuguese language study constituted one whole field of neglect, and that for the entire area only anthropology, geography, colonial history, and literature had received reasonably adequate attention. $(\mathrm{s} / \mathrm{n})$.
} 
número de professores qualificados e de material didático disponível, foi desenvolvida, pelo American Council of Learned Societies. As seis línguas consideradas prioritárias para os investimentos oriundos do NDEA seriam: Árabe, Chinês, Hindu, Japonês, Português e Russo.

Os projetos relacionados à língua portuguesa e aos estudos luso-brasileiros viriam a ser abrigados especialmente pelos programas de bolsas de estudos, de centros de área e de línguas, e de pesquisa e estudos. O título VI, em sua seção 601 (b), prevê a tal autorização:

Pagar estipêndios a indivíduos em treinamento avançado em qualquer língua estrangeira (em relação ao qual ele determine que os indivíduos treinados em tais línguas são demandados pelo Governo Federal ou pelos negócios, indústria, ou educação nos Estados Unidos) e outros campos necessários para a compreensão total da área, região, ou país no qual tal língua é comumente usada, em curto prazo ou nas seções regulares de qualquer instituição de educação superior. (p. 36, tradução nossa). ${ }^{18}$

Por ser pouco ensinada, a língua portuguesa não contava com muitos professores qualificados, ainda mais quando a expectativa era ter a instrução alinhada aos princípios e estratégias da abordagem audiolingual. Em razão disso, ao longo dos primeiros três anos do programa de bolsas de estudos, o português se destacou como alvo de investimentos dentro da área de estudos latino-americanos. Segundo os relatórios consultados, dentre as 107 bolsas concedidas ao abrigo do NDEA para estudos latino-americanos, 105 iriam para profissionais ligados aos estudos da língua portuguesa.

Quanto aos Centros de Língua e Área, o título VI, em sua seção 601 (a), por sua vez, prevê a autorização:

Para providenciar através de contratos com instituições de educação superior o estabelecimento e a operação por elas ... de centros para o ensino de qualquer língua estrangeira em relação a qual o Comissário determinar (1) que os indivíduos treinados em tal língua são demandados pelo Governo Federal ou pelos negócios, indústria, ou educação nos Estados Unidos, e (2) que instrução

\footnotetext{
${ }^{18}$ To pay stipends to individuals undergoing advanced training in any modern foreign language (with respect to which he makes the determination that individuals trained in such language are needed by the Federal Government or by business, industry, or education in the United States) and other fields needed for a full understanding of the area, region, or country in which such a language is commonly used, at any short-term or regular session of any institution of higher education. (p. 36).
} 
adequada em tal língua não está prontamente disponível nos Estados Unidos. (p. 37; tradução nossa). ${ }^{19}$

Como dissemos acima, os projetos relacionados à língua portuguesa foram abrigados pelos programas de bolsas de estudos, de centros, e de pesquisa e estudos. O título VI, em sua seção 602, por sua vez, subsidia este terceiro programa, prevendo a sua autorização:

[...] desenvolver estudos e pesquisas para determinar a necessidade de instrução avançada ou aprimorada em línguas estrangeiras modernas e outros campos necessários para prover compreensão total da área, região, ou país no qual tal língua é comumente usada, conduzir pesquisa sobre métodos mais eficazes de ensino de tais línguas e em tais outros campos, e desenvolver materiais especializados para uso em tal treinamento, ou para treinar professores de tais línguas ou em tais campos. (p. 38; tradução nossa). ${ }^{20}$

Este programa é considerado pelos autores do período como o mais complexo por envolver, em princípio, pesquisa considerada básica na área da psicologia da aprendizagem de línguas, e pesquisa aplicada ao desenvolvimento de materiais didáticos, em especial livros para iniciantes. As consultas feitas aos relatórios do Office of Education revelam que foram submetidos em torno de 120 projetos para a produção de material de ensino de línguas.

No que diz respeito à qualidade da instrução, um dos objetivos do NDEA, não foi possível encontrar estudos que tratem dessa complexa questão com o rigor científico necessário. O que os autores de artigos do período dizem é que o ensino de línguas não só teria avançado quantitativa, mas também qualitativamente. Tal afirmação tem como base os aspectos mensuráveis da situação ensino-aprendizagem de línguas, notadamente a formação de professores, recursos eletromecânicos e materiais didáticos.

${ }^{19}$ To arrange through contracts with institutions of higher education for the establishment and operation by them. [...] of centers for the teaching of any modern foreign language with respect to which the Commissioner determines (1) that individuals trained in such language are needed by the Federal Government or by business, industry, or education in the United States, and (2) that adequate instruction in such language is not readily available in the United States. (p. 37).

${ }^{20}[\ldots]$ to make studies and surveys to determine the need for increased or improved instruction in modern foreign languages and other fields needed to provide a full understanding of the areas, regions, or countries in which such languages are commonly used, to conduct research on more effective methods of teaching such languages and in such other fields, and to develop specialized materials for use in such training, or in training teachers of such languages or in such fields. (p. 38). 
Para melhorar a formação dos professores de línguas, alguns cursos intensivos foram desenvolvidos na forma de institutos. Tratava-se de familiarizar os professores com as estratégias de ensino da abordagem audiolingual e, ao mesmo tempo, de desenvolver a competência linguística de cada um para o uso da língua estrangeira em sua modalidade oral. Os relatórios sobre as atividades dos institutos dão conta da participação de muitos professores em vários cursos oferecidos por universidades do país como na Universidade do Texas, em 1959, por exemplo:

Alinhado com este propósito [elevar os padrões do nosso ensino de língua] o Instituto de Verão de Língua Estrangeira da Universidade do Texas buscou ajudar os setenta e oito professores secundários matriculados a melhorar as suas qualificações profissionais. (p. 3, tradução nossa). ${ }^{21}$

Convém também destacarmos, tomando ilustrativamente o mesmo relatório da Universidade do Texas, o objetivo expresso do Instituto desdobrado em correspondente programa. Como podemos facilmente depreender da citação abaixo, a ênfase na oralidade e nos aspectos culturais do programa supõe o desconhecimento da língua estrangeira por boa parte dos professores em formação. Ao mesmo tempo, podemos perceber que conteúdos relacionados à natureza da língua e ao seu ensino indicam o lugar destacado da Linguística Aplicada, em particular como subsídio à compreensão da abordagem audiolingual.

(1) Questões profissionais envolvendo as melhores formas de integrar o ensino de língua com outras partes do currículo escolar foram trabalhadas em curso chamado Bases Profissionais do Ensino de Línguas Estrangeiras (2 horas por semana)

(2) Para utilizar as contribuições da linguística em relação à natureza da língua e do ensino de língua nós incluímos um curso sobre as Bases Linguísticas do Ensino de Línguas (3 horas por semana) (3) Questões de motivação, métodos e de materiais foram tratadas tanto de forma teórica quanto prática. (15 horas por semana) (4) As necessidades individuais dos cursistas para melhorar o seu comando da segunda língua e adquirir uma melhor compreensão da cultura foram os objetivos do curso Treinamento Avançado (5 horas por semana). Além disso, muito tempo para auto aprimo-

${ }^{21}$ In line with this purpose [to raise the standards of our language teaching] The University of Texas Summer Institute in Foreign Language sought to help the seventy-eight secondary school enrollees improve their professional qualifications. (p. 3). 
ramento for dado nas salas de compreensão oral, no laboratório de línguas, e em pequenas sessões de drilagem e de grupos de discussão. (p. 3). ${ }^{22}$

A maioria das universidades que ofereceram cursos como este aqui brevemente apresentado reapresentariam propostas semelhantes a editais de fomento a programas de línguas estrangeiras nos anos que se seguiram. A experiência que ganharam essas instituições serviu-lhes para desenvolver iniciativas que se tornariam verdadeiros marcos na história do PLE. Referimo-nos especialmente ao Modern Portuguese Project e ao seu produto maior - um livro didático de mesmo nome - que podem ser considerados como o projeto da Modern Language Association. Desenvolvido a partir da constituição do Portuguese Language Development Group (Grupo de Desenvolvimento da Língua Portuguesa), liderado por profissionais da Universidade do Texas em Austin, o projeto caracteriza-se como resultado de uma associação de professores e pesquisadores de português, entre os quais profissionais brasileiros, cujo objetivo expresso e amplamente difundido era vitalizar e expandir os estudos de língua portuguesa nos Estados Unidos.

\section{Considerações FinAis}

A reconstrução do clima de opinião das décadas de 40, 50 e 60, com foco na formação de professores de português nos Estados Unidos, objetivo deste artigo, desenvolveu-se a partir de publicações como livros e artigos de periódicos e jornais da época. Escritos por profissionais da área de línguas e também de negócios internacionais e política externa, esses documentos apresentam volume e consistência suficientes para serem tomados como expressão do clima de opinião do período.

22 (1) Professional questions involving the best ways of integrating language teaching with other parts of the school curriculum were dealt with in course entitled Professional Bases of Foreign Language Teaching. (2 hours a week).

(2) In order to utilize the insights of linguistic science concerning the nature of language and language learning we included a course on the Linguistic Bases of Foreign Language Teaching. (3 hours a week).

(3) Questions of motivation, methods, and materials were treated, both theoretically and practically. (15 hours a week).

(4) The individual needs of trainees to improve their control of the second language and in acquiring a better understanding of the culture were the objectives of the course Advanced Language Training ( 5 hours a week). In addition, much time for self-improvement was provided in the listening rooms, in the language laboratory, and in small drill and discussion groups. (p. 3). 
Podemos também antecipar que o cruzamento dos achados relativos ao clima de opinião de períodos mais recentes e dos dias atuais, com aqueles referentes ao crescimento da oferta e da demanda de cursos de português nos Estados Unidos aponta, preliminarmente, para uma relação direta entre os mesmos. Podemos, assim, considerar que a reconstrução de uma prática pedalinguística, como a do PLE, apoia-se em uma rede de fatores políticos, sociais e educacionais, que influem diretamente no conteúdo do ensino, como, por exemplo, a escolha de uma variante e na sua evolução, bem como na formação e manutenção de um corpo docente.

Entendemos que o presente trabalho se justifica objetivamente pela contribuição que deve representar para a Historiografia e para a Linguística Aplicada. Para gerações de linguistas aplicados, pretendemos oferecer, com a memória referente ao ensino de PLE, um subsídio fundamental para o desenvolvimento de pesquisas linguísticas diversas. Para a HL, pretendemos evidenciar uma forma de como a história do PLE e da formação de professores pode ser abordada.

Finalmente, por ser o ensino de uma língua uma matéria também central para historiadores das culturas (SWIGGERS, 1990), com o presente estudo pretendemos, ainda, contribuir tangencialmente para a história da presença da língua portuguesa e do Brasil nos Estados Unidos.

\section{REFERÊNCIAS}

BERRIEN, William. The Study of Portuguese. In: DOYLE, Henry. (Org.). A Handbook on the Teaching of Spanish and Portuguese With Special Reference to Latin America. Boston: D.C. Heath and Company, 1945. p. 47-49.

HAMILTON, Daniel Lee. Modern Foreign Languages and NDEA, Title VI. Higher Education, v. XIX, n. 9, p. 3-37, 1963.

HUTTON, Eddie. The Value of the Study of Spanish and Portuguese. In: DOYLE, Henry. (Org.). $A$ Handbook on the Teaching of Spanish and Portuguese With Special Reference to Latin America. Boston: D.C. Heath and Company, 1945. p. 20-43.

JOHNSTON, Marjorie. How can Modern Language Teaching Promote International Understanding? The Bulletin of the National Association of Secondary - School Principals, v. 40, n. 224, p. 70-85, 1956.

KOERNER, Konrad. Models in Linguistic Historiography. In: KOERNER, K (Ed.). Practicing Linguistic Historiography: selected essays. Amsterdam: John Benjamins Publishing Company, 1989. p. 47-59.

.Persistent issues in linguistic historiography. In: Professing Linguistic Historiography. Amsterdam/Philadelphia: John Benjamins Publishing Company, 1995. p. 3-26.

LETGERS, Lyman H. The National Defense Education Act and Latin American Studies. Austin: Institute of Latin American Studies, University of Texas, 1965. 
MILLER, Charles. The Place of Portuguese in American Education. Education A Monthly Magazine, v. 62, n. 6, p. 351-353, 1942.

NICHOLS, Madaline. The History of Spanish and Portuguese Teaching in the United States. In: DOYLE, Henry (Org.). A Handbook on the Teaching of Spanish and Portuguese With Special Reference to Latin America. Boston: D.C. Heath and Company, 1945. p. 99-146.

PARKER, William Riley. The National Interest and Foreign Languages: Washington: U.S. Govt. Print Off, 1961.

PEI, Mario. The Function of Languages in the Post-War World. The Modern Language Journal, v. XXVIII, n. 3, p. 280-285, 1944.

PROPOSAL FOR and NDEA Center of Latin American Language and Area Studies at The University of Texas Department of The University of Texas. January 29 to August 31, 1962.

PUBLIC PAPERS. Dwight D. Eisenhower. Reassurance speech. Washington, D.C., 1957. p. 817.

ROBY, Elizabeth. Vocational Opportunities for Students of Spanish and Portuguese. In: DOYLE, Henry. (Org.). A Handbook on the Teaching of Spanish and Portuguese With Special Reference to Latin America. Boston: D.C. Heath and Company, 1945. p. 53-81.

SWIGGERS, Pierre. Histoire et Historiographie de l'enseignement du français: modèles, objets et analyses. Ėtudes de Linguistique Appliquée, v. 78, p. 27-44, 1990.

TELLER, Edward. We Have Suffered A Very Serious Defeat. U.S News and World Report, Washington, p. 65, 15 de nov. 1957.

United States Office of Education. The National Defense Education Act of 1958. United States Government Printing Office. Washington: 1958.

Submetido em: 18/10/2011

Aceito em: 10/12/2012 